\title{
INTERMIDIALIDADE COMO PROCESSO DE RESSIGNIFICAÇÂO NARRATIVA EM DIE BRÜCKE
}

\section{INTERMEDIALITÄT ALS PROZESS DER NARRATIVEN WIEDERBEDEUTUNG IM DIE BRÜCKE}

\author{
Gabriel Felipe Pautz Munsberg ${ }^{184}$
}

RESUMO: Com o final da Segunda Guerra Mundial, as artes alemãs libertaram-se da censura e posicionaram-se contrárias à guerra, como é o exemplo do romance Die Brücke (A ponte, 1958), de Manfred Gregor, e sua adaptação fílmica homônima, de Bernhard Wicki (1959). O presente trabalho pretende elencar, ainda que de forma sucinta, as articulações entre (e intra-)mídias - a saber: intertextualidade, transposição, referência e combinação de mídias - realizadas pelo cinema, através de linguagem própria. Para tal análise, o embasamento teórico apropriado remete-se às teorias de intermidialidade (Rajewsky, 2012) e intertextualidade (Samoyault, 2008).

Palavras-chave: Cinema; intermidialidade; literatura.

ZUSAMMENFASSUNG: Am Ende der Zweite Weltkrieg befreiten die deutschen Kunst von der Zensur und bezogen Stellung gegen der Krieg, zum Beispiel der Roman Die Brücke (1958) von Manfred Gregor und sein gleichlautender Verfilmung von Bernhard Wicki (1959). Dieser Abschnitt behümt sich um die Beziehung zwischen (und innere-)Medien auflisten das heißt: Intertextualität, Medienwechsel, Intermediale Bezüge und Medienkombination - die das Kino in seiner eigenen Sprache gemacht hat. Bei der Analyse bezieht sich der theoretische Hintergrund auf die Theorien von Intermedialität (Rajewsky, 2012) und Intertextualität (Samoyault, 2008).

Schlüsselwörter: Film, Intermedialität; Literatur.

184 Doutorando em Estudos da Literatura - Teoria, Crítica e Comparatismo, pela Universidade Federal do Rio Grande do Sul 
Um pequeno rio de calmas correntezas é bombardeado por um projétil oriundo de algum avião que não se vê, apenas se ouve. A bomba não faz estrago à nada sólido, apenas joga água para cima que logo se volta ao curso natural do rio. Com um travelling da câmera para cima, enxergase agora uma também pequena ponte de pedra intacta. Esta é a cena de abertura de "Die Brücke" (por vezes traduzido literalmente como "A ponte", em outras como "A ponte da desilusão"), filme alemão antiguerra de 1959 do diretor Bernhard Wicki. Baseado no romance homônimo - e em parte autobiográfico - do jornalista Gregor Dormeister (sob o pseudônimo de Manfred Gregor), publicado no ano anterior. O filme mostra as experiências de um grupo de jovens alemães durante o final da Segunda Guerra Mundial. A película ganhou o prêmio de Melhor filme estrangeiro no Globo de Ouro de 1960, assim como recebeu indicação na mesma categoria no Oscar do mesmo ano ${ }^{185}$.

O plot narrativo do filme fundamenta-se na convocação de sete jovens alemães para as Wehrmacht (Forças Armadas) em abril de 1945, medida tomada pelo exército alemão no momento em que a Alemanha Nazista encontrava-se praticamente derrotada na Segunda Guerra Mundial. Colegas na escola secundária, os jovens de 16 anos mostram-se ansiosos e animados com a convocação, apesar dos apelos de suas mães e do professor Stern, o qual intercede pela liberação dos adolescentes diretamente com o chefe da companhia, capitão Fröhlich, em que comparecem. Cada um dos garotos possui uma caracterização diferente, através da qual o espectador pode criar um sentimento de empatia com um ou mais personagens do filme.

Sigifried Bernhard é o mais novo do grupo, ainda com 15 anos. Enquanto seu pai está lutando, Sigi vive com sua mãe, a qual deseja que o filho se esconda com uma tia por algumas semanas. Porém, Sigi responde a este pedido "Assim vou acabar desertando! O que meus companheiros vão pensar?". Facilmente influenciado pelas brincadeiras dos colegas, "nosso anão", como é chamado pelos maiores, é representado seguidamente lendo um livro, quando civil, ou apenas sentado esperando que algo lhe seja ordenado.

Jürgen Borchert, por sua vez, é descendente de uma família de oficiais, tendo seu pai falecido em guerra. Ao lado de sua mãe, mantem

185 Em 2008 foi gravado um remake de mesmo nome, com direção de Wolfgang Panzer e roteiro de Wolfgang Kirchner, fortemente criticado pela mídia alemã. 
Intermidialidade como processo de ressignificaçâo narrativa em Die Brücke | 397

uma fazenda, na qual trata arrogantemente os trabalhadores estrangeiros. Jürgen acredita em tudo que seu pai lhe transmitiu e, dos jovens, é o que tem maior crença na luta do exército nacional, dando a entender que todos sacrifícios da sociedade se valem para a vitória nazista.

Walter Forst é filho do Ortsgruppenleiter (líder local do partido nazista), contra o qual possui rivalidade em função da covardia do pai. Apesar da proximidade lógica com as regras rígidas do partido, Walter é "um porco que não acredita em nada”, como diz Jürgen. Em seu quarto, entre fotos de combatentes, um par de luvas de boxe e discos de jazz fazem parte da decoração, evidenciando sua rebeldia para com as proibições nazistas.

O outro jovem que vive com o pai é Karl Horber. Possui interesse na ajudante do pai na barbearia, mas, ao saber do relacionamento de ambos, entra em conflito com o pai, tomando a convocação para a guerra como uma forma de afastar-se do convívio com eles.

Klaus Hager e Hans Scholten foram evacuados de suas cidades e sobre os quais não possui maiores informações. Klaus mora com a família da única garota da turma de escola, Franziska, com quem possui um relacionamento. Hans é o mais maduro dos jovens, tomando a liderança do grupo nos momentos decisivos. Ele mora com Albert Lutz e sua mãe, a qual confia em Hans a segurança do filho após a convocação à guerra. $\mathrm{O}$ pai de Albert, assim como o de Sigi, está no front e a família não recebe notícias suas há 23 dias. Albert, que gostaria de ser maquinista, é o jovem que menos se arrisca nos confrontos com os americanos, permanecendo sempre ao lado de Hans.

Este grupo de adolescentes, influenciado pela literatura e cinema da época (não devemos esquecer da censura e manipulações realizadas pelo Ministério da Propaganda do Terceiro Reich, através de Joseph Goebbels desde 1933), possui uma noção deturpada da guerra. Walter Benjamin, ao discutir sobre o cinema, em A obra de arte na era de sua reprodutibilidade técnica [1935], aponta que "o consumo de uma quantidade avassaladora de acontecimentos grotescos no cinema é uma drástica evidência dos perigos que ameaçam a humanidade nas repressões que a civilização traz consigo”. (BENJAMIN, 2013, p. 85)

Uma noite após a apresentação dos jovens, as tropas nazistas são ordenadas a irem para o front, porém o capitão Fröhlich ordena ao sargento Heilmann, como forma de evitar a morte desnecessária dos recém-convocados, que fique com os adolescentes numa pequena ponte da aldeia. Os garotos reclamam pela distância em que se encontram do 
front, ao que Heilmann responde: "Atrás estão os melhores postos, como no cinema. Adiante tem excesso de luz". Esta ponte, do ponto de vista da estratégica bélica, é praticamente inútil, uma vez que os americanos já haviam cruzado o rio em outra parte de sua extensão e que ela seria implodida pelos próprios nazistas após a evacuação dos soldados feridos. Dessa forma, ainda durante a primeira madrugada o sargento Heilmann sai em busca de café para o grupo, deixando para trás sua arma. Dentro da cidade, ele é interpelado por policiais que o acusam de deserção e, na fuga, o sargento é morto a tiros.

Mesmo com a discussão sobre a possível deserção do sargento e dos avisos de civis sobre a retirada das Forças Armadas da cidade, os jovens permanecem sozinhos na ponte, organizando trincheiras e pontos estratégicos para eventuais conflitos, determinando, a partir do "compromisso nacional" e da recusa de serem covardes, que Jürgen será o líder do grupo. A partir deste momento, os adolescentes deparam-se com os horrores da guerra real, primeiro na morte do mais jovem dos soldados, Sigi, ao ser atingido mortalmente em um ataque aéreo e, logo em seguida, ao verem os soldados mutilados em caminhões que passam pela ponte. Na sequência, os americanos chegam à localidade em tanques e são recebidos por tiros de metralhadoras e bazucas antitanques por parte dos seis jovens restantes. Antes da batida em retirada dos americanos, os jovens Jürgen, Walter, Karl e Klaus perdem suas vidas, deixando a ponte para trás com os últimos dois jovens restantes, Hans e Albert.

Quando três oficiais nazistas chegam à ponte para sua implosão, os dois adolescentes discutem sobre a ordem de proteção da mesma e, para salvar o colega sob a pontaria de uma arma, Albert atira pelas costas contra um dos oficiais, fazendo com que os outros fujam, porém não sem antes alvejarem mortalmente Hans. Por fim, Albert tenta levar Hans para dentro da cidade, mas o colega morre em seus braços e ele segue seu caminho sozinho, enquanto a câmera realiza uma tomada aérea mostrando a ponte intacta e, na sequência, os dizeres "Isto ocorreu em 27 de abril de 1945. Foi tão insignificante que não foi mencionado em nenhum comunicado especial".

Assim como a água volta ao seu fluxo habitual após a bomba cair no rio, na sociedade acontece uma (tentativa de) normalização do cotidiano após a guerra. Apesar da guerra causar danos permanentes, tanto psicológicos quanto físicos, procura-se minimizar o que se passou em busca de um distanciamento dos traumas por ela originados. A morte, por exemplo, é banalizada durante um período de violência extrema. Isso 
Intermidialidade como processo de ressignificaçâo narrativa em Die Brücke | 399

se evidencia ao tomarmos as mortes dos seis soldados adolescentes defendendo uma ponte inútil.

Três décadas antes, em 1929, um ex-soldado alemão de nome Erich Paul Remarck publicava as experiências de um soldado na Primeira Guerra Mundial até sua morte, em casa, durante uma reserva temporária. Nada de novo no front, de Erich Maria Remarque, possui linguagem simples e emotiva para desenvolver a trivialidade da guerra. A morte do soldado Paul é descrita de forma simplória: "Tombou morto em outubro de 1918, num dia tão tranqüilo em toda a linha de frente, que o comunicado limitou-se a uma frase: "Nada de novo no front". (REMARQUE, 2004, p. 143-144)

Percebe-se, portanto, uma transposição do livro de Erich Maria Remarque ao livro de Manfred Gregor e, consequentemente, ao filme de Bernhard Wicki. Ambos escritores foram soldados durante as duas grandes guerras e seus textos acabam por discutir a banalização, tanto dos civis quanto dos militares, sobre a guerra e suas consequências. "O leitor está a todo tempo pronto para tornar-se um escritor" (BENJAMIN, 2013, p. 78) e é dessa maneira, portanto, que Gregor se apropria, à sua forma, da nota final de Nada de novo no front em seu romance. Compreendendo a repetição do desastre do indivíduo nos processos bélicos que se sucedem na Alemanha, Gregor recupera e atualiza o texto de Remarque. Tiphaine Samoyault vê na intertextualidade a "memória melancólica" de um grupo que se reconhece, em variados níveis, no texto anterior.

As práticas intertextuais informam sobre o funcionamento da memória que uma época, um grupo, um indivíduo têm das obras que os precederam ou que lhe são contemporâneas. Elas exprimem ao mesmo tempo o peso desta memória, a dificuldade de um gesto que se sabe suceder a outro e vir sempre depois. (SAMOYAULT, 2008, p. 68)

As guerras geram o mesmo sentimento de pequenez e insignificância aos seus participantes, assim como a perplexidade em lidar com os fatos quando estanques, de forma que a linguagem não consegue dar conta das experiências. Nesse sentido, no ensaio "Experiência e pobreza", de 1933, Walter Benjamin relata como os combatentes da Primeira Guerra Mundial voltavam "mais pobres em experiências comunicáveis, e não mais ricos" (BENJAMIN, 2012, p. 115), apesar de toda gama de experiências e estratégias às quais foram postos, ou seja, a 
experiência da guerra não reflete beneficamente na experiência de vida dos soldados.

A despeito deste declínio da experiência, de acordo com Benjamin, os escritores do pós-guerra lutam novamente, agora com palavras, para expor suas vivências. Transmitir estes relatos consiste, naturalmente, em ficcionalizar a realidade, independente da classificação textual resultante. Se estabelecermos de fato a experiência da guerra como algo impensável e, consequentemente, irrepresentável, sua representação só pode se dar ao planeá-la em um pensamento consolidado, ou seja, "a lógica do irrepresentável só se sustenta numa hipérbole que afinal a destrói". (RANCIÈRE, 2012, p. 148)

Já o cineasta Bernhard Wicki realiza outro movimento, não de todo diferente em relação à apropriação de um texto. Ao adaptar em filme o texto de Gregor. Wicki realiza, portanto, uma transposição midiática (Medienwechsel) na qual transforma o romance escrito - mídia texto - numa sequência de imagens - mídia fílmica. $O$ filme surge então como novo texto, sem que afete necessariamente o significado do romance em sua formação, o que o filólogo Werner Wolf (2005) determina como uma "intermidialidade extracomposicional" (apud. RAJEWSKY, 2012), portanto, com diferenças estruturais e narrativas.

Ao comparar as narrativas de Gregor e Wicki de Die Brücke, Lukas Bartholomei (2015) aponta, por exemplo, para a questão da infantilidade dos jovens ser mais fortemente explorada no cinema quanto ao livro. A mais notável diferença encontrada entre as obras é a linearidade narrativa: enquanto o romance de Gregor inicia-se já com os adolescentes envolvidos com o trabalho militar e retorna no tempo conforme a necessidade de explicações sobre o passado dos personagens, o filme de Wicki propõe-se a uma narrativa linear. A adaptação possui, portanto, independência em relação ao texto "original" sobre o qual fundamenta sua narrativa.

O cinema não é uma língua, sem dúvida nenhuma, mas pode ser considerado como uma linguagem, na medida em que ordena elementos significativos no seio de combinações reguladas, diferentes daquelas praticadas pelos idiomas e que tampouco decalcam a realidade. Assim, sendo uma linguagem, permite uma escrita, isto é, o texto fílmico. (METZ apud. CUNHA, 2010, p. 77) 
Intermidialidade como processo de ressignificaçâo narrativa em Die Brücke | 401

A narrativa linear de Wicki, portanto, possibilita um enfoque diferenciado aos acontecimentos do filme, pois "as imagens do cinema são antes de mais nada operações, relações entre o dizível e o visível, maneiras de jogar com o antes e o depois, a causa e o efeito" (RANCIÈRE, 2012, p. 14). Apesar do cinema dispor de procedimentos narrativos que possibilitam o retorno ao passado - flashback - como realizado na literatura, o diretor apresenta os acontecimentos com os jovens em sequência cronológica, optando por mostrar que as decisões tomadas neste caso são irreversíveis, tal qual a correnteza do rio que abre o filme. Outro procedimento referente ao tempo utilizado no cinema recai sobre a duração das montagens do filme.

A primeira parte do filme - cerca de um terço do mesmo envolve apenas a apresentação dos sete jovens envoltos em seus círculos sociais como escola, casa e lazer. Este período permite que o espectador consiga desenvolver uma identificação com algum dos personagens, ou até mesmo com o grupo em geral, ou até mesmo se solidariza com os jovens frente às situações que enfrentam. Já na sequência seguinte, na qual os jovens se apresentam às Forças Armadas, recebem treinamento e são enviados à ponte, pouco se modificada, visto que a caracterização inicial vai sendo ratificada em relação ao que os jovens diziam pensar sobre a guerra, tratando-a ainda como uma "brincadeira de índios".

No entanto, a ruptura entre a imaginação dos jovens e a realidade da guerra é a morte de Sigifried, em decorrência de um ataque aéreo. Os garotos não têm tempo para lamentar a morte do colega, pois o ruído de tanques inimigos se aproximando da ponte faz com que os jovens soldados tomem seus postos e iniciem o confronto. É a partir deste momento, porém, nos cerca de 20 minutos finais da película, que as cenas finalmente propiciam ação ao filme. A cada jovem morto, percebese que o combate só se encerrará com a aniquilação total dos personagens. Sendo assim, o filme de Wicki conduz seu espectador por cerca de 80 minutos em uma diegese sossegada até que a confusão surge através de, novamente, um ataque aéreo, modificando a velocidade da narrativa, e encerre o relato em tom de perplexidade. $O$ crítico francês Marcel Martin aponta em A linguagem cinematográfica (2011), que o espectador terá seu pressentimento de tempo transcorrido influenciado também por ações específicas:

A intuição da duração depende da maneira como o espectador é afetado pela totalidade dramática da ação: diante de uma ação muito violenta ou muito rápida, parece 
que o tempo passa depressa, mas se o espectador se interroga em seguida sobre sua própria impressão, será levado a pensar (por reação) que a ação real é mais longa do que aquela que percebeu. É indispensável frisar, porém, que a tonalidade dramática de uma ação é menos uma questão de quantidade (número de acontecimentos) que de qualidade (densidade e intensidade dos fatos representados). (MARTIN, 2011, p. 261)

O uso de técnicas audiovisuais próprios do cinema, sobretudo o som nesta parte final do filme, ilustra a rapidez e variação narrativas. Enquanto a chegada dos tanques é evidenciada com o barulho opressivo dos motores e do vento, os closes nos adolescentes, além de mostrar claramente a apreensão em seus rostos, são calcados num silêncio apreensivo, no que se pode contrastar a opressão dos movimentos bélicos e o consentimento e/ou inocência dos jovens. $\mathrm{O}$ único disparo realizado pelo primeiro tanque destrói a barricada em frente à ponte, o que novamente mostra a falta de aptidão dos adolescentes no confronto com a realidade. $\mathrm{O}$ som reverbera novamente quando do confronto armado entre alemães e americanos.

Durante a troca de tiros, a câmera propicia o revelar dos sentimentos dos adolescentes através de closes, como, por exemplo, no sorriso de Jürgen ao atingir um soldado inimigo. No momento em que o esconderijo de Jürgen é descoberto pelos inimigos, ele é alvejado e morre, para o horror de Albert e Klaus que desejam sair das trincheiras, mas são dominados por Hans e Karl. Walter já havia cruzado a linha de fogo e entrado em uma construção próxima aos tanques, mas é encontrado pelos soldados americanos que percebem que os inimigos consistem em adolescentes. Por ventura de um disparo de tanque, o teto da construção cai, matando Walter. Um dos soldados americanos sai da construção gritando aos jovens que parem de atirar, pois crianças deveriam ir para casa ou para um jardim de infância ${ }^{186}$. Ao ouvir estas palavras, Karl sai da

186 "Hey, stop shootin"! Come on, give up! We don't fight kids! Go home... or go to... kindergarden!“. O cognato kindergarden (inglês) - Kindergarten (alemão) faz com que Karl lembre-se da fala de seu pai a sua ajudante Barbara, por quem o adolescente nutre sentimentos, após ter o relacionamento entre ambos descoberto: "Pensava que já era um homem. E esses meninos 
Intermidialidade como processo de ressignificaçâo narrativa em Die Brücke | 403

trincheira para atacar o soldado americano, que é alvejado na barriga. A dor agonizante do soldado faz com que Klaus entre em desespero e peça a Karl para que atire novamente no soldado, afim de acabar com seu sofrimento, porém os inimigos já haviam matado também a Klaus.

Nesse momento, a imagem de um pequeno filete de sangue escorrendo do nariz de Karl remete ao momento em que Klaus havia lhe dado um soco, quando Karl fala que todas as mulheres, inclusive Franziska, eram sem-vergonhas. Karl mostra-se arrependido, desejando que Klaus pudesse lhe devolver o soco e, em frenesi, sai da trincheira sendo morto pelo fogo inimigo. A súbita raiva de Karl (ao lembrar das palavras do pai) e o desespero de Klaus em sua morte (pesaroso pela agressão na escola) não são explicadas verbo ou visualmente pelo filme através de flashbacks. Como dito anteriormente, esta opção narrativa do diretor, apoiada na atuação enérgica dos jovens, cimenta a irreversibilidade frente às ações impensadas da sociedade.

Aqui entra em ação a câmera, com seus meios auxiliares seu descer e subir, seu interromper e isolar, sua dilatação e compressão do ocorrido, seu ampliar e reduzir. Somente por meio dela chegamos a conhecer o inconsciente óptico, assim como conhecemos o inconsciente pulsional por meio da psicanálise. (BENJAMIN, 2013, p. 84)

Os closes nos rostos dos jovens durante as cenas de confronto mostram a surpresa e o desespero com a realidade mortífera da guerra, principalmente se comparados aos momentos civis dos garotos. Ainda na escola, durante a última aula de inglês que o grupo participou antes da convocatória, Hans lia versos de "Romeu e Julieta", de William Shakespeare, enquanto o resto da turma permanecia em silêncio prestando atenção aos versos. As imagens mostram os garotos visivelmente sublimados com os versos apaixonados de Julieta, contrastando o romantismo da literatura com a violência das trincheiras.

Em relação às referências à literatura no filme, temos em Sigifried o personagem de maior contato com livros durante sua representação civil. Os livros servem ao garoto como fuga da realidade e, somada à sua inocência e solubilidade de influências, a literatura atua na

querem se mandar para a guerra? A esta idade não se vai a um quartel. Se vai a um jardim de infância!". 
404 | Gabriel Felipe Pautz Munsberg

homogeneização da vida real no mundo da ficção. Após o rasante do avião inimigo na ponte e a troça dos colegas, Sigi busca atuar com uma bravura digna de ficção ao enfrentar em pé os disparos aéreos. A expressão impávida de seu rosto falecido revela uma morte igualmente tranquila, sem medos e muito menos covardia.

Ironicamente, a leitura é vista pelos jovens de formas diferentes. $\mathrm{Na}$ última noite em casa, Albert e Hans arrumam suas malas envoltos em suposições:

Hans: "Para que quer esta faca? Vai brincar com os índios?" Albert: "O chefe da estação disse-me que à noite não se atira, que se ataca com arma branca"

Hans: "Que besteira. [Vira-se para a mãe de Albert:] Ele tem lido muitas novelas".

Já enquanto os jovens realizam a limpeza das armas, Walter explica aos colegas que o facão não é bem afiado para que, em combate, o estrago provocado no inimigo seja maior:

Walter: "Se estivesse tão afiado como uma navalha, entraria e sairia com toda facilidade. No que isto entrar na barriga, pode-se dizer adeus"

Sigi: "Na barriga?"

Walter: "Onde, se não? Tem que apoiar com toda forca com um pé para poder tirar."

Klaus: "Como sabe?"

Walter: "Tenho lido."

Assim sendo, a menção à literatura, ou leitura de ficções, durante o filme é vista como uma referência intermidiática (intermediale Bezüge), conforme Irina Rajewsky. Esta composição pode afetar a performance da mídia filme, "já que a interpretação dessas referências em toda sua potencialidade funcional vai depender, necessariamente, do reconhecimento prévio das diferenças midiáticas pertinentes" (RAJEWSKY, 2012, p. 65). O dispositivo livro tende a provocar um miseen-scène no qual o espectador é remetido ao mundo da literatura e fantasia, desconectando o personagem e suas percepções da realidade; entretanto, sua simples referência pode passar nula a outro espectador e acabar resultando em outra interpretação. 
Intermidialidade como processo de ressignificaçâo narrativa em Die Brücke | 405

A cena de Walter em seu quarto na última noite antes de se apresentar às Forças Armadas é singela neste sentido. As paredes do quarto são decoradas por fotos de soldados e luvas de boxe e Walter ouve jazz enquanto se embebeda com as bebidas de seu pai. Cabe ao espectador relacionar o contexto da casa do líder local do NSDAP com luvas de boxe e discos de jazz. Apesar do uso da figura do campeão dos pesos-pesados Max Schmeling ${ }^{187}$ por parte dos nazistas para a consagração da raça ariana, o boxe foi dominado por pugilistas norte-americanos na década de 1940. O jazz, por conseguinte, foi um estilo musical marcado pela propaganda nazista como "arte degenerada", uma vez que suas origens e maiores popularidades remontem a comunidades de negros americanos, desenvolvendo-se através de tradições de religiões afro-americanas.

Em outro exemplo de referência intermidiática, o comandante Fröhlich cita uma estrofe do poema "Der Tod fürs Vaterland" ("A morte pela pátria", 1800) - "A batalha é nossa! Vivei acima, oh Pátria, e não contai os mortos. Para ti, amor, não importa nenhum sacrifício!”188 - ao professor Stern, o qual intercede por seus alunos. O uso do poema como slogan nacional-socialista, mostra também a utilização da literatura e filosofia realizada pelos intelectuais nacional-socialistas para propagandear seus mitos. Novamente, cabe ao espectador compreender a relação de Hölderlin ao nazismo, o contexto de escrita do poema e da recepção do mesmo no cenário alemão em que o filme se desenrola.

${ }^{187}$ Maximillian Schmeling (1905-2005) foi campeão dos pesos-pesados em 1930 e 1931. Em junho de 1936, venceu o americano Joe Louis em Nova Iorque, sendo esta luta tomada pelos nazistas como propaganda de seus ideais. Apesar de recusar ingressar no partido nazista ou demitir seu empresário judeu, além de ser casado com uma tcheca de origem judia desde 1933, o pugilista era seguidamente visto ao lado membros importantes do partido, como o próprio Adolf Hitler. Em 1938, porém, Schmeling perdeu a revanche contra Joe Louis, sendo a transmissão da luta via rádio cortada para o território alemão. As SS também descobriram que o pugilista era colaborador de refugiados judeus e, assim que a guerra iniciou, Schmeling foi recrutado pelos nazistas como paraquedista e enviado a missões suicidas.

${ }^{188}$ Tradução livre de "Die Schlacht / ist unser! Lebe droben, o Vaterland, / und zähle nicht die Toten! Dir ist, / Liebes! nicht Einer zu viel gefallen". (HÖLDERLIN, 1954, p. 121) 
A conjuntura da Propaganda nazista merece um comentário, ainda que sucinto, em vista de suas práticas intermidiáticas. Tomada como "a linguagem da sedução" (CARVALHO, 2010), a publicidade consiste em um texto com objetivo de cativar, deslumbrar ou até mesmo corromper seu leitor. Portanto, a propaganda trata-se de um discurso e, como tal, argumentativo e até mesmo impositivo. Na mescla de um texto do gênero publicitário com outros textos ou mídias variadas o resultado é uma combinação de mídias (Medienkombination). Com a finalidade de difundir valores ideológicos, o uso da literatura na propaganda não cria uma nova mídia, mas passa então a fazer parte da publicidade, já que o texto publicitário permanece com seu objetivo definido, mesmo com mudança de configuração estilística.

A escrita, por outro lado, é uma mídia separada e particular. Ela pode ficar transparente na leitura de um texto impresso convencionalmente: para muitos leitores a fonte e o tamanho das letras normalmente não influenciam na recepção e interpretação do texto verbal (mas podem influenciar no prazer da leitura). Mas, além de existir em muitas formas de representação da linguagem verbal alfabética, ideogramática, hieroglífica, cuneiforme, etc. escrita, manual ou impressa, consiste de signos sui generis, com um grande leque de expressividade. (CLÜVER, 2011, p. 13)

Fluente em sua própria linguagem, o cinema articula, portanto, variadas mídias para expor a mensagem narrativa pretendida ao espectador. Bernhard Wicki, como consequência do aprofundamento das técnicas cinematográficas possiveis, adapta o romance de Manfred Gregor apresentando em Die Brücke sua visão da catástrofe do pós-guerra alemão. Mesmo ao final desta ainda rasa análise, podemos tomar como conclusão que essa narrativa fílmica absorve suas influências midiáticas e as verte em uma linguagem própria da qual o espectador tem permissão para beber tudo o que lhe emerge. 
Intermidialidade como processo de ressignificaçâo narrativa em Die Brücke | 407

\section{REFERÊNCIAS}

BARTHOLOMEI, L. Bilder von Schuld und Unschuld: Spielfilme über den Nationalsozialismus in Ost- und Westdeutschland. Münster: Waxmann Verlag, 2015.

BENJAMIN, W. A obra de arte na era de sua reprodutibilidade técnica. Trad. Gabriel Valladão Silva. Porto Alegre: L\&PM, 2013.

BENJAMIN, W. Pobreza e experiência. In: Magia e técnica, arte e politica: ensaios sobre literatura e história da cultura. Trad. Sérgio Paulo Rouanet. São Paulo: Brasiliense, 2012.

CARVAlHO, N. de. Publicidade: a linguagem da sedução. São Paulo: Ática, 2010.

CLÜVER, C. Intermidialidade. In: Pós. Belo Horizonte, v.1, n.2, Nov. 2011.

CUNHA, J. M. dos S. Comparatismos e mídias: transferências e interferências textuais. In: SCHMIDT, R. T. (org.). Sob o signo do presente: intervenções comparatistas. Porto Alegre: Editora da UFRGS, 2010.

FRANKFURTER ALLGEMEINE ZEITUNG. Die Lebensstationen von Max Schmeling: Max Schmelings Leben und Wirken im Überblick. Disponível em <http://www.faz.net/-gtl-py3n〉. Acesso em 02 de março de 2016.

HÖLDERLIN, F. Der Tod fürs Vaterland. In: Gesammelte Werke (1954). Disponivel em <http://gutenberg.spiegel.de/buch/friedrich-h262/70>. Acesso em 04 de março de 2016.

MARTIN, M. A linguagem cinematográfica. Trad. Paulo Neves. São Paulo: Brasiliense, 2011.

RAJEWSKY, I. O. A fronteira em discussão: o status problemático das fronteiras midiáticas no debate contemporâneo sobre intermidialidade. Trad. Isabella Santos Mundim. In: DINIZ, T. F. N.; VIEIRA, A. S. (orgs.). Intermidialidade e estudos interartes: desafios da arte contemporânea. Belo Horizonte: Rona Editora: FALE/UFMG, 2012.

RANCIÈRE, J. O destino da imagem. Trad. Mônica Costa Netto. Rio de Janeiro: Contraponte, 2012.

REMARQUE, E. M. Nada de novo no front. Trad. Helen Rumjanek. Porto Alegre: L\&PM, 2004.

SAMOYAUlT, T. A intertextualidade. Trad. Sandra Nitrini. São Paulo: Aderaldo \& Rotschild, 2008. 
408 | Gabriel Felipe Pautz Munsberg

Recebido em: 25/08/2019

Aceito em: 15/09/2019

Caderno de Letras, no 34, Maio-Ago - 2019 - ISSN 0102-9576 